\title{
Associations between immune competence, stress responsiveness, and production in Holstein-Friesian and Holstein-Friesian $\times$ Jersey heifers reared in a pasture-based production system in Australia
}

\author{
J. W. Aleri, ${ }^{1,2,3 *}$ B. C. Hine, ${ }^{4}$ M. F. Pyman, ${ }^{2}$ P. D. Mansell, ${ }^{2}$ W. J. Wales, ${ }^{5}$ B. Mallard, ${ }^{6}$ M. A. Stevenson, ${ }^{2}$ \\ and A. D. Fisher ${ }^{2,3}$ \\ ${ }^{1}$ College of Veterinary and Life Sciences, Murdoch University, 90 South Street, Murdoch, Western Australia 6150, Australia \\ ${ }^{2}$ Faculty of Veterinary and Agricultural Sciences, University of Melbourne, 250 Princes Highway, Werribee, Victoria 3030, Australia \\ ${ }^{3}$ Animal Welfare Science Centre, University of Melbourne, Victoria 3010, Australia \\ ${ }^{4}$ CSIRO Agriculture, Armidale, New South Wales 2350, Australia \\ ${ }^{5}$ Agriculture Research and Development Division, Department of Economic Development, Jobs, Transport and Resources, Ellinbank, \\ Victoria 3821, Australia \\ ${ }^{6}$ Department of Pathobiology, Ontario Veterinary College, University of Guelph, Ontario NIG2W1, Canada
}

\section{ABSTRACT}

The objectives of this study were to assess antibody and cellular immune responses in first-lactation dairy heifers reared under a pasture-based production system and to investigate associations between immune competence and stress responsiveness, health, and productivity. A commercial vaccine was used to induce antibody and cellular immune responses and, based on measured responses, animals were classified as above average, average, and below average for each trait independently and in combination (overall immune competence). Overall immune competence phenotypic rankings were generated by combining standardized residual values for antibody and cellular responses measured in individual heifers. Cortisol responses to handling and yarding were used to assess stress responsiveness, worm egg counts were used to assess internal parasite burden, somatic cell counts to assess udder health and estimates of total daily milk volume, and milk fat and milk protein contents to assess productivity. A total of 393 Holstein-Friesian and Holstein-Friesian $\times$ Jersey crossbred heifers from 2 herds practicing seasonal calving in a pasture-fed production system were enrolled in the study. The immune competence phenotypes of individual heifers were assessed before their first mating and their subsequent performance during their first lactation was monitored. Animals with below-average antibody and cellular immune competence had higher serum cortisol concentrations compared with their counterparts following handling, suggesting they had a reduced ability to cope with management-induced

Received February 12, 2018.

Accepted December 5, 2018.

*Corresponding author: J.Aleri@murdoch.edu.au stress. Furthermore, a significant negative (favorable) correlation was observed between antibody responses and stress responsiveness. Similarly, correlations between antibody responses and internal parasite burden were significant and negative (favorable). No correlations were observed between overall immune competence and milk yield, milk fat, and milk protein content. Key words: antibody, immune responses, cortisol response, somatic cell counts, worm egg counts

\section{INTRODUCTION}

The welfare of dairy cattle may be compromised during the periparturient period due to the increased incidence of health disorders, such as mastitis, milk fever, retained fetal membranes, and gastrointestinal conditions, observed during this period (Uribe et al., 1995; Berry et al., 2003; Cummins et al., 2012). Furthermore, increased incidence of these disorders during the periparturient period has a significant negative effect on herd profitability (Kossaibati and Esslemont, 1997). Previous selection for production traits, with limited emphasis on survival and longevity traits, is thought to have contributed to the increased incidence of periparturient health problems observed in modern dairy cows (Miglior et al., 2005; Oltenacu and Broom, 2010). It has also been shown that modern dairy cattle can experience a prolonged state of periparturient immunosuppression that can result in increased periparturient health disorders (Aleri et al., 2016).

Testing immune competence has the potential to identify livestock with an enhanced ability to resist disease (Burton et al., 1989; Pighetti and Sordillo, 1996; Wagter et al., 2003) and allows selection emphasis to be placed on ability to cope with disease challenges in conjunction with other desirable production and fitness traits (Hine et al., 2014). It is important to note 
that several countries already routinely incorporate longevity and survival traits in their breeding programs (Cummins et al., 2012; Moore et al., 2014). The inclusion of immune competence traits in breeding programs is expected to provide a holistic health approach in the improvement of dairy cattle health and welfare (Hine et al., 2014). Immune competence testing, as described here, combines measures of both antibody and cellular immune responses in an effort to predict the overall immune capacity of each individual animal. Cellular and antibody responses are most effective at controlling intra- and extracellular pathogens, respectively, and work in coordination to protect the host (Colditz and Hine, 2016). The magnitude of antibody and cell-mediated immune responses in dairy cattle have been shown to be negatively genetically correlated (Thompson-Crispi et al., 2012b). Therefore, selecting animals based on their resistance to specific disease(s) may inadvertently increase susceptibility toward other diseases most effectively controlled by different arms of the immune system. For example, in a recent study in dairy cattle, it was observed that cows most susceptible to tuberculosis, a disease largely controlled by cellular responses, had a lower incidence of mastitis, a disease largely controlled by antibody responses (Edwards, 2014). A similar relationship has been reported in cattle selected for resistance or susceptibility to Brucella abortus (brucellosis; Price et al., 1990). Innate host defense mechanisms are also critical for early pathogen detection, clearing foreign organisms, and steering the adaptive immune responses (Mallard et al., 2015); therefore, assessing combined indicators of immune competence is expected to identify animals with improved overall disease resistance (Thompson-Crispi et al., 2012a,b; Mallard et al., 2015). Data from intensive Canadian dairy systems have shown cows ranked as high immune responders to have a lower incidence of periparturient diseases than their low-responder counterparts (Thompson-Crispi et al., 2012a), although did not differ in their productivity when parameters describing milk volume or fat and protein content were compared (Stoop et al., 2016). In pasture-based production systems in Australia, heifers with enhanced immune competence were observed to have higher growth rates (Aleri et al., 2015). Favorable associations between disease resistance and stress responsiveness have also been reported in pigs (Hessing et al., 1994, 1995). Data on associations between immune competence, disease incidence, and production traits in typical pasture-based dairy production systems are limited. Therefore, an improved understanding of the relationships that exist between immune competence, stress responsiveness, and productivity in dairy cattle in pasture-based production systems is required to aid in the development of effective breeding strategies aimed at improving the immune competence of dairy herds.

Studies in the intensive Canadian dairy systems have used specialized antigens to induce measurable immune responses when assessing immune responsiveness in dairy cattle. Here, we describe a methodology to assess immune competence in dairy cattle that uses a commercial vaccine to induce measurable responses rather than specialized test antigens. This methodology avoids issues associated with the use of nonregistered products in food-producing animals, a practice that is highly regulated in Australia and other parts of the world. The successful use of this methodology has been reported previously (Aleri et al., 2015, 2017; Aleri, 2016).

With this background, the specific objectives of our study were to assess the immune competence of dairy heifers reared under a pasture-based production system before their first mating and investigate associations between immune competence, stress responsiveness, udder health (individual cow SCC), and production traits (milk and milk fat and protein yields). We hypothesized that enhanced immune competence would be favorably correlated with stress responsiveness, health, and productivity.

\section{MATERIALS AND METHODS}

\section{Study Area and Ethics Approval}

This study was conducted at Colac, Victoria, Australia $\left(38^{\circ} 20^{\prime} 20^{\prime \prime} \mathrm{S}, 143^{\circ} 34^{\prime} 55^{\prime \prime} \mathrm{E}\right)$, in accordance with the Australian Code of Practice for the Care and Use of Animals for Scientific Purposes (National Health and Medical Research Council, 1990) with the approval of the Animal Ethics Committee of the University of Melbourne (approval no. 1312823.3).

\section{Study Design}

This was a prospective cohort study conducted from April 2013 to April 2015 investigating production and health performance in dairy heifers grouped based on their rank for the immune competence traits and antibody, cellular, and overall immune responsiveness. Associations between immune competence trait phenotype rankings, health [individual SCC and worm egg counts (WEC)], cortisol response to handling, and productivity (milk and milk fat and protein yield) were investigated.

\section{Herd Selection}

Animals used in the study were from 2 dairy herds and represented typical large-scale pasture-based dairy systems in Australia. Both herds practiced seasonal 
calving and heifers were reared in a pasture-based production system. In this type of production system, cows predominately graze pasture to meet their nutritional requirements, with occasional supplementation with other forages and with grain or concentrate supplementation when required (Wales and Kolver, 2017). Herd selection for the study was purposive (nonprobabilistic) and based on the willingness of the herd managers who met the selection criteria to participate in the study. Herd selection criteria included (1) the presence of a seasonal or split calving regimen; (2) the presence of a reliable animal identification system; and (3) regular use of herd testing or the presence of in-line milking meters to allow estimation of individual cow daily milk volume yields. The herds enrolled in the study practiced twice-a-day milking (morning and evening). In both herds, cows were culled if they were observed to have clinical mastitis (observable physical changes in milk), with the aim of maintaining the herd's bulk tank SCC below 250,000 cells/mL. Treatment of clinical cases of mastitis occurred only occasionally in adult cows. Mastitis control in Australian dairy farms is supported by the Countdown Downunder national program for mastitis control (Brightling et al., 2009). In the enrolled farms, other mastitis control strategies included pre- and postmilking teat disinfection, use of dry cow therapy, use of teat sealants in heifers, and regular maintenance of milking equipment.

All animals in both herds were immunized with a commercial combined clostridial/leptospirosis vaccine (Ultravac 7 in 1, Zoetis, West Ryde, NSW, Australia) at $8 \mathrm{wk}$ of age (before enrollment into the study) as part of routine disease management practices. This same vaccine was used in immune competence testing procedures; therefore, immune responses assessed as part of the immune competence phenotyping in the current study represent secondary immune responses to the vaccine antigens. All animals in both herds received anthelmintic treatment (Ivermectin preparations, International Animal Health Products Pty Ltd., Huntingwood, New South Wales, Australia) at 6 to 8 wk of age and again at 5 to 6 mo of age (before enrollment into the study) to control internal parasites.

\section{Sample Size Calculations}

Power calculations before the study was conducted showed that a total of 350 animals would be required to achieve a study power of 0.80 , assuming the proportion of animals observed with disease in the below-average immune response group was $25 \%$ and the proportion of animals observed with disease in the above-average and average immune response group was $10 \%$ using a 2 -sided test with significance level of 0.05 . Calcula- tions assumed 5 times as many animals were in the below-average immune response group compared with the above-average and average immune response groups combined. The sample size was adjusted to allow a $10 \%$ inclusion for losses due to follow-up; hence, a total of 385 animals was deemed appropriate. Sample size calculations were carried out using the Power and Sample Size Program version 3.0 (Dupont and Plummer, 1990). The study power defined the probability of detecting a statistical difference, if in existence, between study subjects and quantified by a certain magnitude as I $\beta$, where $\beta$ is type 11 error; this produced a $31 \%$ chance of false-negative results (Dohoo et al., 2012).

\section{Enrolment of Study Subjects}

A total of 393 yearling heifers aged 12 to 15 mo were enrolled in the study before their first mating. These included 195 and 198 heifers enrolled from herds 1 and 2, respectively. All heifers in herd 1 were purebred Holstein-Friesians, whereas heifers in herd 2 were both purebred Holstein-Friesians $(\mathrm{n}=151)$ and HolsteinFriesian $\times$ Jersey crossbreds $(n=47)$. All heifers were immune competence tested before their first mating and thereafter followed until end of their first lactation cycle. In the course of the follow-up period from testing to the end of their first lactation, 87 animals were culled due to various reasons. Postmating, herd 1 culled 60 animals due to financial reasons. Among these culled animals, the selection criteria on which animals were culled was based on limited pedigree data (parental lineage information) and their predicted performance information. Withdrawal of animals postcalving occurred based on decisions made by participant herd managers to cull individuals due to mastitis or low production ( $\mathrm{n}=13$ and 14 from herds 1 and 2, respectively). Therefore, milk yield data for only 306 of the 393 heifers were available and comprised estimates of 305-d milk volume, milk fat and protein yields, and individual SCC. Post hoc power calculations revealed that the data consisting of 306 study subjects used to generate results on the herd tests achieved a power of 0.69 with a relative risk of 2.5 in the below-average immune responders $(\mathrm{n}=51)$ compared with average and above average immune responders $(\mathrm{n}=256)$. The culling of animals during the follow-up period reduced the power of the data generated from the herd test results by approximately $14 \%$ (from 80 to $69 \%$ ).

\section{General Data Collection}

All heifers were immune competence tested as yearlings when 12 to 15 mo of age before their first mating by assessing both antibody and cellular immune 
responses to vaccination. Following testing, heifers were ranked based on either antibody, cellular, or overall immune response, which combines measures of both antibody and cellular responses. Subsequently, health and production performance was recorded throughout the first lactation. Calvings occurred over a 3 -mo period on both farms.

\section{Immune Competence Testing}

Test Antigens. The immune competence testing involved assessing both antibody and cellular immune responses. In the protocol, responses to a commercial clostridial/leptospirosis vaccine (Ultravac 7 in 1, Zoetis) were used to induce measurable immune responses to assess immune competence. According to the manufacturer, the vaccine contained an antigenically balanced mixture of Clostridium perfringens $(\geq 5 \mathrm{IU} / \mathrm{mL})$, Clostridium tetani $(\geq 2.5 \mathrm{IU} / \mathrm{mL})$, Clostridium novyi type B $(\geq 3.5 \mathrm{IU} / \mathrm{mL})$, and Clostridium septicum $(\geq 2.5 \mathrm{IU} / \mathrm{mL}$; as UF toxoids), a purified formol culture of Clostridium chauvoei $0.3 \mathrm{~mL} / \mathrm{mL}$, and formalin-killed cultures of Leptospira borgpetersenii serovar Hardjo type hardjo $\geq 400 \times 10^{6}$ organisms $/ \mathrm{mL}$ and Leptospira interrogans serovar Pomona $400 \times 10^{6}$ organisms $/ \mathrm{mL}$. The vaccine also contained an adjuvant consisting of aluminum salts and thiomersal as a preservative.

Immune Competence Testing Protocol. Each animal was immunized on $\mathrm{d} 0$ of the testing period with $2.5 \mathrm{~mL}$ of Ultravac 7 in 1 vaccine injected subcutaneously high on the neck, as per the manufacturer's instructions (https://www.zoetis.com.au/product-class -new/vaccines/ultravac-7in1.aspx). In an attempt to limit the effects of potential differences in previous exposure to antigens present in the commercial vaccine used in testing, each farm was fitted as a fixed effect in statistical models, with all animals on a given farm being raised in a single contemporary group from birth to testing. Briefly, animals were vaccinated and to assess antibody responses, blood was collected preimmunization at $\mathrm{d} 0$ (baseline) and postimmunization at d 8 and 10 for serum antibody level testing. Before analysis, a randomly selected subset of $\mathrm{d} 8$ and 10 serum samples from individual heifers were analyzed to determine which day more accurately reflected peak antibody responses to immunization. Based on results obtained from this subset of samples, we decided to use d-10 serum samples to assess antibody responses, as responses were significantly higher in samples collected at d 10 as compared with d 8. Blood samples were collected by caudal venipuncture and serum prepared by centrifugation for $15 \mathrm{~min}$ at $700 \times g$ (at room temperature). To assess cellular responses, $0.1 \mathrm{~mL}$ of the vaccine was injected intradermally into the caudal fold on the right side of the tail (test) and $0.1 \mathrm{~mL}$ of saline solution on the left side of the tail (control) on d 8; the magnitude of the cutaneous hypersensitivity reactions was assessed as the change in skin fold thickness from d 8 to 10 (48 h later) at the test site relative to the control site.

Antibody Responses. Production of tetanus toxoid-specific serum $\operatorname{IgG}_{1}$ antibody in response to immunization was used to assess antibody production. Levels of serum antibody were determined on d 0 (baseline), 8, and 10 using an ELISA. The ELISA procedure was optimized to maximize sensitivity while minimizing background signal. Before analysis, a randomly selected subset of samples were titrated to determine the most appropriate sample dilutions for the assay. Briefly, plates were coated with tetanus toxoid antigen (0.2 Lime flocculation units/well, donated by Zoetis) in carbonate buffer and incubated at $4^{\circ} \mathrm{C}$ overnight. Plates were then blocked with PBS containing $1 \%$ casein for $2 \mathrm{~h}$ at room temperature. Plates were washed once with PBS containing $0.05 \%$ Tween (PBST) and control and test serum samples were added to wells in quadruplicate. Serum (control and test samples) were diluted $1 / 40$ and $1 / 160$ in PBS containing $1 \%$ casein and $0.05 \%$ Tween (diluent), added to plates and incubated for $1 \mathrm{~h}$ at room temperature. Plates were washed 5 times with PBST and a secondary antibody (sheep anti-bovine $\operatorname{IgG}_{1}$ conjugated to alkaline phosphatase, Bio-Rad Laboratories Inc., Hercules, CA) diluted in Tris-buffered solution containing $0.05 \%$ Tween 20 (pH 7.4) and $1 \%$ casein was added to plates and incubated at room temperature for $1 \mathrm{~h}$. Plates were washed 5 times in PBST and P-nitrophenyl phosphate substrate (Sigma-Aldrich, St. Louis, MO) was added. Following incubation in a dark at room temperature, optical density values were measured at a wavelength of $405 \mathrm{~nm}$ with a reference wavelength of $630 \mathrm{~nm}$. Mean sample optical density readings were calculated for each dilution $(1 / 40$ and $1 / 160)$ of each sample. The associated coefficient of variation (CV) for each sample dilution was also calculated. Therefore, the CV (using a minimum of triplicate values) was calculated for each sample at each dilution; where a CV of less than $10 \%$ was not achieved, analysis of the sample was repeated until a CV of less than 10\% was achieved for both dilutions. Subsequently, to assess antibody responses (Heriazon et al., 2009; Thompson-Crispi et al., 2012a) the optical density values from the $1 / 40$ and $1 / 160$ dilutions of each sample run in the ELISA assays were summed and corrected to the rolling mean (or average value for control samples observed across all plates) of the positive and negative controls run on all plates. This correction was conducted to minimize effects of plateto-plate variation, as described previously (Hine et al., 
2011). Therefore, corrected values for control samples run on all plates were the same. The control samples were also run in quadruplicate and CV assessed similar to the study samples. The mean $\mathrm{CV}$ for the positive and negative control samples run across all plates was 4.17 and $3.97 \%$, respectively, representing the interplate variation. The negative control sample was prepared by pooling serum collected from heifers prevaccination, whereas the positive control sample was prepared by pooling samples collected from heifers on d 10 postvaccination.

Assessing Cellular Responses. The magnitudes of the cutaneous hypersensitivity reactions were assessed as a measure of cellular immune responses. Due to the complex mix of vaccine antigens used in skin testing procedures, reactions could be expected to represent a combination of innate type responses and classical delayed-type hypersensitivity (DTH) reaction responses. Although unconfirmed in dairy cattle, our group has assessed skin reactions to the clostridial vaccine components used here in yearling beef cattle at $6,12,24$, and $48 \mathrm{~h}$ postinjection. Results demonstrated that the magnitude of responses continually increased from 6 to $48 \mathrm{~h}$ postinjection, with maximal responses observed at $48 \mathrm{~h}$, suggesting that the cellular response observed using the testing methodology described here are consistent with a classical DTH response (data not shown). On d 8 of the test period, baseline skin-thickness measures were taken in triplicate at the proposed injection sites on the left and right tail folds using spring-loaded calipers (Harpenden skin fold calipers; Creative Health Products Inc., Ann Arbor, MI). Intradermal injections $(0.1 \mathrm{~mL})$ of Ultravac 7 in1 (test) and saline (control) were then administered to the right and left tail fold, respectively. On d 10, at $48 \mathrm{~h}$ postinjection, triplicate skin thickness measurements were again taken at the control and test injection sites. The magnitude of skin reactions were calculated as previously described (Begley et al., 2009a,b). Briefly, the increase in skin thickness from 0 to $48 \mathrm{~h}$ at the test site was corrected for the increase in skin fold thickness at the control site using the formula

$$
\text { Increase }(\mathrm{mm})=(\mathrm{A}-\mathrm{B})-(\mathrm{C}-\mathrm{D}),
$$

where $\mathrm{A}=$ mean test site thickness at time $48 \mathrm{~h} ; \mathrm{B}=$ mean of test site thickness at time $0 \mathrm{~h}$; $\mathrm{C}=$ mean of control site thickness at $48 \mathrm{~h}$; and $\mathrm{D}=$ mean of control site thickness at $0 \mathrm{~h}$.

Assessing Overall Immune Competence. Overall immune competence (OIC) measures were obtained from combining antibody and cellular immune responses as described in the Statistical Analyses section.
Stress Responsiveness. In the current study, stress responsiveness was assessed by measuring cortisol responses to handling. Serum cortisol concentrations on d 8 and 10 following mustering, yarding, and handling were used to assess stress responsiveness. Serum cortisol levels were expected to rise within 1 to $3 \mathrm{~min}$ of handling. To collect serum for cortisol assessment, heifers in groups of 20 were mustered to a holding pen and subsequently run through a race and had blood collected from the tail vein by 5 experienced technicians. Blood samples were collected from all 20 heifers within a period of 4 to $5 \mathrm{~min}$. Thereafter, skin fold tests and injections for DTH reactions were conducted for each animal one at a time while they were restrained in a crush.

Serum cortisol concentrations were analyzed by the Research Laboratory at the School of Agriculture and Environment, University of Western Australia (Crawley), using the methodology described by Beausoleil et al. (2008). Briefly, plasma cortisol was measured using a radioimmunoassay kit (Cortisol GammaCoat RIA kit CA-1549, Dia Sorin Inc., Stillwater, MN) with a limit of detection of $3.5 \mathrm{nmol} / \mathrm{L}$. Serum samples were assayed in duplicate and cortisol concentrations determined by preparing a standard curve with standards of known concentrations ranging from 3.5 to $1,655 \mathrm{nmol} / \mathrm{L}$. Quality control samples were included in each assay run to monitor performance of the assay. The interassay CV was 3.3 and $4.0 \%$ for the low and high control samples, respectively.

Internal Parasite Burdens. Fecal samples were collected directly from the rectum of all heifers on d 0 of the immune competence testing and individual WEC conducted using the McMaster technique (Kassai, 2002). In addition, fecal culture and worm larval identification was conducted on pooled samples from each herd to identify nematode species present, as described previously Kassai (2002).

Herd Tests and Follow-Up. The periparturient period in our study was defined as 3 wk before and after the calving date for each heifer in each of the 2 herds. Each herd was visited 2 to $3 \mathrm{~d} /$ wk during the periparturient period (3 mo), followed by visits every 1 to 2 wk throughout the entire lactation period. From approximately 2 mo postcalving, milk volume, milk fat, milk protein, and SCC were measured for individual animals every 2 mo as part of routine herd testing procedures by the Herd Improvement Cooperative Australia (Victoria, Australia) for herd 1 or the Australian Dairy Herd Improvement Scheme (Melbourne, Australia) for herd 2. Dates and details of heifers that left the herd as either culls or deaths were recorded. Management procedures undertaken on animals within 
each respective herd were recorded during the entire duration of the follow-up period.

\section{Statistical Analyses}

Data were analyzed using IBM SPSS Statistics (Version 22.0, IBM Corp., Armonk, NY). Data were assessed for outliers and normality by plotting frequency histograms and using the Shapiro-Wilk and Kolmogorov-Smirnov tests. Only data on WEC required transformation and were log-transformed $[\log ($ WEC + 50)]. Phenotypic rankings for cellular and antibody immune responses were generated as described by Hine et al. (2011). Briefly, measures of cellular and antibody responses were analyzed using a model in which the fixed effects of herd (herd 1 and 2) were fitted and residual values (observed - predicted) for each individual animal generated for each trait. In the analysis of antibody responses in serum collected on d 10 postimmunization, d-0 measures were fitted as a covariate. Breed was assessed as a fixed effect for data collected from herd 2. We identified no statistically significant association between antibody response and breed; therefore, breed was excluded subsequent statistical analyses. Residuals values for both antibody (tetanus toxoid-specific serum $\mathrm{IgG}_{1}$ production in response to immunization assessed on d 10) and cellular responses (magnitude of DTH responses assessed on d 10) obtained from statistical models were standardized (to have a mean of 0 and SD of 1 ). For each respective trait, animals with a residual value below -1 were ranked as below average, those between -1 and 1 as average, and those greater than 1 as above average for the trait. Overall immune competence phenotypic rankings were generated by summing standardized residual values for antibody and cellular responses and ranking as below average, average, and above average (using criteria above), as described previously (Hine et al., 2011). Two scenarios were assessed in our analyses. In the first scenario, group differences between above-average, average, and below-average animals based on antibody, cellular, or OIC rankings were investigated. In the second scenario, group differences between above-average and average animals combined into a single grouping (superior competence animals) versus below-average immune competence animals were investigated. The second approach was used to estimate the potential effects of removing below-average immune competence animals from the herd and retaining average and above-average (superior immune competence) animals, which represented the likely scenario of what would occur in industry.

Estimates of 305-d milk volume and milk fat and milk protein were computed based on the individual cow herd test data collected throughout each cow's lac- tation using the methodology described by Kirkpatrick et al. (1990) implemented in the epi.ltd procedure in the epiR package (Stevenson et al., 2015) in $\mathrm{R}$ version 3.1.3 (R Foundation for Statistical Computing, Vienna, Austria).

Separate linear regression models were used to determine correlations between immune competence (cellular, antibody, and OIC) and stress responsiveness (cortisol concentrations following mustering and handling), resistance to internal parasites (WEC), and herd performance traits (305-d milk volume and milk fat and milk protein). Immune competence measures for cellular, antibody, and OIC were fitted as outcome variables, whereas stress responsiveness, resistance to internal parasites, and herd performance traits were tested as the explanatory variables. Measures of WEC were transformed $[\log (\mathrm{WEC}+50)]$, and the transformed data were used in all analyses. In a separate scenario, a logistic regression model was used to analyze WEC data, which were converted to a binary trait with presence of any WEC denoted as 1 and absence as 0 for the estimation of the odds of having WEC based on immune response group.

Multivariate modeling was used to analyze differences in stress responsiveness, resistance to internal parasites, and herd performance traits between above-average, average, and below-average immune competence animals (based on cellular, antibody, and OIC) and also superior (above average and average) versus belowaverage immune competence animals. Generalized linear models (GLMM) were used to make comparisons between immune competence phenotype groups while controlling for the fixed effect of herd. The influence of variables on the outcome (immune competence expressed as either antibody, cellular, and OIC, stress responsiveness as assessed by serum cortisol concentration, or herd production data including milk yield, composition, and SCC) were tested by constructing a series of single explanatory variable GLMM. Explanatory variables that were associated with the outcome at $P<0.2$ were then retained for multivariable modeling. The outputs from the multivariable GLMM provided estimates of the effect of each explanatory variable on the outcome, adjusting for the fixed effects of herd. A repeated measures procedure was used to analyze data on SCC and stress responsiveness (repeated measures of cortisol concentrations) under the GLMM framework with animal fitted as a random effect. Before the analysis of SCC data, values were converted to linear scores (LS; Schukken et al., 2003). The LS was a base 2 logarithmic conversion of SCC. Cow LS was calculated as $\mathrm{LS}=\log _{2}(\mathrm{SCC} / 100)+3$, where SCC data were expressed in cells per liter. Although the proportion of heifers culled for mastitis was low $(8.1 \%, 27 / 333)$, SCC 
data from these heifers were not available and were therefore excluded from analysis. Thus, limitations to what can be interpreted from analysis of SCC data are acknowledged. Therefore, in addition to analysis of SCC data, the odds of being culled due to clinical mastitis was analyzed using odds ratios. For odds ratio analysis, culling (due to clinical mastitis) was fitted as an outcome variable whereas immune response groups of antibody, cellular, and OIC responses were fitted as explanatory variables.

\section{RESULTS}

\section{Immune Competence}

Animals in each phenotype were grouped for antibody (above average, $\mathrm{n}=71$; average, $\mathrm{n}=260$; below average, $\mathrm{n}=61$ ), cellular (above average, $\mathrm{n}=56$; average, $\mathrm{n}=292$; below average, $\mathrm{n}=44$ ), and OIC ranking (above average, $\mathrm{n}=90$; average, $\mathrm{n}=198$; below average, $\mathrm{n}=101$ ). Simple linear regression analysis showed that cellular and antibody immune competence were not phenotypically correlated $(P=0.24)$.

\section{Stress Responsiveness}

Cortisol concentrations on d 8 (mean $=63.66 \pm 1.75$ $\mathrm{nmol} / \mathrm{L})$ and $10($ mean $=76.37 \pm 1.87 \mathrm{nmol} / \mathrm{L})$ were high and variable, suggesting that mustering and handling of heifers in the current study induced a stress response. Furthermore, serum cortisol concentrations were significantly greater on d 10 (mean $=76.37 \pm$ $1.87 \mathrm{nmol} / \mathrm{L}, \mathrm{n}=392)$ compared with $\mathrm{d} 8$ (mean $=$ $63.66 \pm 1.75 \mathrm{nmol} / \mathrm{L}, \mathrm{n}=392)$, with a mean difference of $12.71 \mathrm{nmol} / \mathrm{L}(95 \% \mathrm{CI}=8.61-16.81 \mathrm{nmol} / \mathrm{L}$; $P<0.0001)$ suggesting a significant increase in stress responses at $d$ 10. A significant negative correlation between repeated measurements of serum cortisol concentrations following mustering and handling (d 8 and 10) and antibody immune response $(\mathrm{r}=-0.220, P<0.01)$ was observed. In contrast, correlations between cortisol concentrations and cellular immune response and OIC were weak and nonsignificant $(\mathrm{r}=0.07 ; P=0.083$ and $\mathrm{r}=-0.086 ; P=0.088$, respectively. Correlations between stress responses (d 10) and immune competence (antibody, cellular, and OIC) are presented in Figure 1. A summary of differences in stress responsiveness between immune competence phenotype groupings is presented in Table 1. Multivariate modeling for stress responsiveness identified no significant differences between immune competence phenotype groups when animals were grouped on antibody, cellular, or OIC ( $P$ $=0.112,0.937$, and 0.447 , respectively). Similarly, no significant differences in cortisol response were observed between superior (above average and average) and below-average immune competence phenotype groups for antibody, cellular, and OIC $(P=0.070,0.066$, and 0.365 , respectively). Animals that were below average for both antibody and cellular immune competence had higher stress responses when compared with their counterparts that were either average or above average for at least 1 of the immune competence traits $(P=$ 0.006; Table 2).

\section{Internal Parasite Burden}

The WEC were generally low, with a mean of 21 (range $=0-360$ ). Fecal samples were cultured and larval differentiation identified the presence of Cooperia species (C. punctata, C. oncophora, and C. pectinata) and a small number of Coccidia oocytes. A significant but weak negative correlation between antibody immune response and WEC (transformed values) was observed $(\mathrm{r}=-0.108, P=0.017)$. No correlations with cellular immunity $(\mathrm{r}=-0.009, P=0.432)$ or OIC $(\mathrm{r}=-0.051$, $P=0.157$ ) were observed (Figure 2). Odds ratios were used to assess the odds of the presence of WEC in below-average, average, and above-average responders for cellular, antibody, and OIC groups. A total of $72 \%$ $(281 / 393)$ of animals had a zero WEC. Differences in WEC between animals categorized as above average and average compared with below average for cellular, antibody, and OIC immune competence measures were not significant, with odds ratios of $1.14(95 \% \mathrm{CI}=$ $0.54-2.40), 1.81(95 \% \mathrm{CI}=0.81-4.03)$, and $0.85(95 \%$ $\mathrm{CI}=0.44-1.66)$, respectively.

\section{Mastitis and SCC}

The incidence of clinical mastitis observed over the duration of the study period was $8.1(95 \% \mathrm{CI}=5.6-11)$ cases per 100 cows, with 27 of 333 heifers observed to have mastitis. The incidence of mastitis in herds 1 and 2 was $10.4(95 \% \mathrm{CI}=6.3-17)$ and $6.6(95 \% \mathrm{CI}=3.9-11)$ cases per 100 cows, respectively. Heifers were suffering from mastitis when physical changes in milk quantity, consistent with mastitis, were observed. As part of standard health management procedures in both herds, all heifers with mastitis were immediately culled from the herd, precluding additional follow-up information being collected on these heifers. Individual cow linear SCS for all remaining animals (excluding those culled for mastitis) were within the normal threshold of $<250,000$ cells $/ \mathrm{mL}$ during the lactation cycle, with an average LS of 2.51. Correlations between linear SCS and cellular responses $(\mathrm{r}=-0.023, P=0.433)$, antibody responses $(\mathrm{r}=0.037, P=0.203)$, and OIC $(\mathrm{r}=0.012, P=0.340)$ were not significant. 

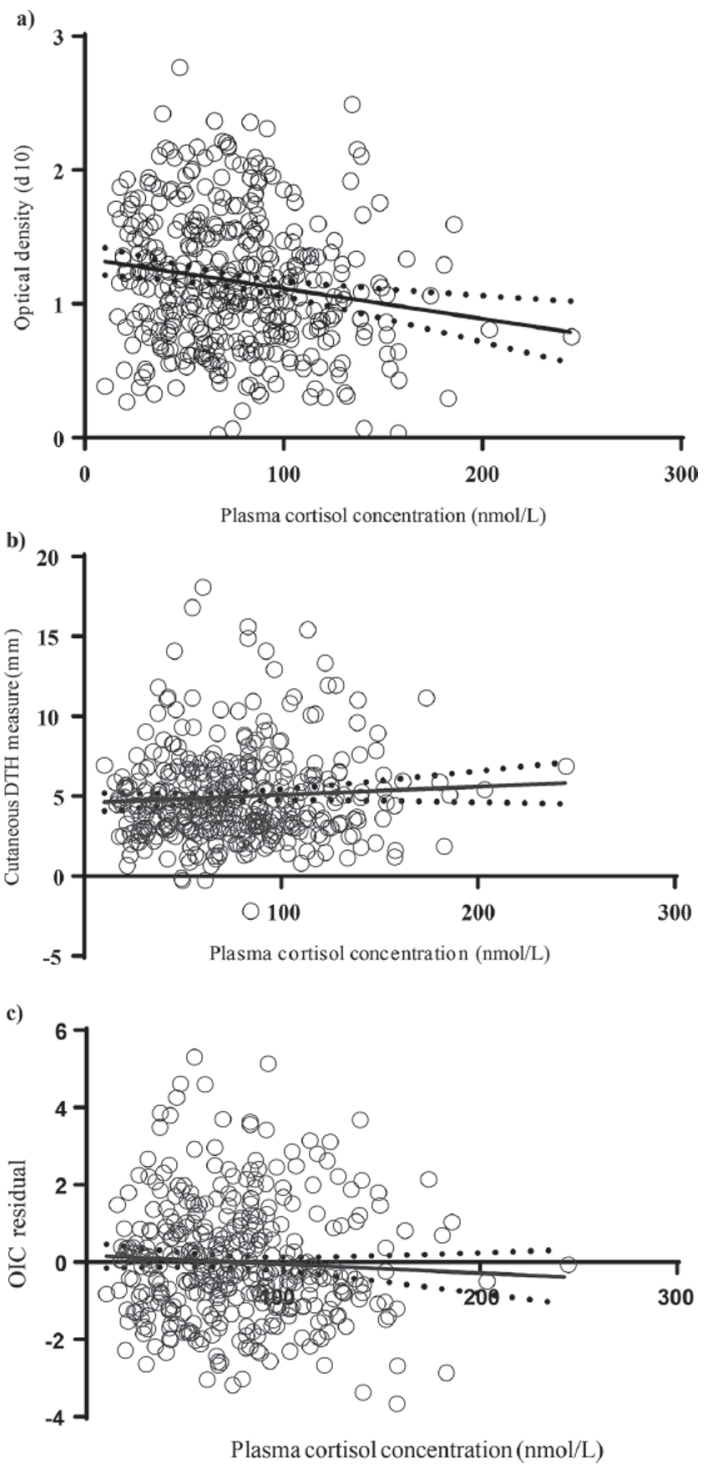

Figure 1. Raw data analysis using GraphPad Prism version 7.00 for Windows (GraphPad Software, La Jolla, CA). (a) Correlation between antibody responses (Ab; d 10), assessed by measuring production of antitetanus toxoid $\mathrm{IgG}_{1}$ serum antibody in response to vaccination presented in optical density units (y-axis) and stress responsiveness (predicted stress responses generated from the linear mixed models for analysis of repeated measures) assessed as the increase in serum cortisol concentrations $(\mathrm{nmol} / \mathrm{L})$ in response to yarding and handling (x-axis). (b) Correlation between cellular immune response assessed by measuring the magnitude of skin reactions to vaccine components (in mm; y-axis) and stress responsiveness (predicted stress responses generated from the linear mixed models for analysis of repeated measures), assessed as the increase in serum cortisol concentrations (nmol/L) in response to yarding and handling (x-axis). Data represent raw (untransformed) values. DTH = delayed-type hypersensitivity. (c) Correlation between overall immune competence (OIC) assessed as combination of measures of antibody and cellular immune response residual values (y-axis) and stress responsiveness (predicted stress responses generated from the linear mixed models for analysis of repeated measures), assessed as the increase in serum cortisol in response to mustering and handling (x-axis). For statistical analysis of correlations between traits, the fixed effects of herd fitted to statistical models as a single factor with 2 levels (herd 1, herd 2). Dotted lines represent $95 \%$ CI.
No significant differences in SCC were observed between above-average, average, and below-average immune competence animals for cellular, antibody, and OIC. However, it is important to consider the practice of culling heifers with clinical signs of mastitis was practiced in study herds when interpreting results. The odds of being culled for mastitis between animals categorized as above average and average compared with below average for immune competence for cellular, antibody, and OIC did not differ significantly [odds ratios of 1.34 $(95 \% \mathrm{CI}=0.51-3.50), 1.49(95 \% \mathrm{CI}=0.54-4.11)$, and $1.33(95 \% \mathrm{CI}=0.52-3.47)$, respectively].

\section{Milk Yield}

Average milk yield to 305 DIM across all heifers was $5,558 \pm 83 \mathrm{~L}$, and mean total milk protein and fat to 305 DIM were $177.56 \pm 2.34$ and $205.79 \pm 2.94 \mathrm{~kg}$, respectively. No correlations were observed between milk yield and antibody response $(\mathrm{r}=-0.021, P=0.389)$ and OIC ( $\mathrm{r}=0.005, P=0.472)$, whereas we noted tendency for a positive trend between milk yield and cellular responses $(\mathrm{r}=0.117, P=0.061)$. No significant differences in total milk yield to 305 DIM were observed between above-average, average, and below-average immune competence animals when classified by cellular, antibody, and OIC $(P=0.418,0.725$ and 0.806 , respectively). No significant differences were observed in milk protein between animals ranked based on immune competence $(P=0.354,0.155$, and 0.573 for ranking on cellular, antibody, and OIC, respectively) and milk fat yields $(P=0.810,0.186$, and 0.506 for cellular, antibody, and OIC, respectively). Correlations between milk protein yield and cellular, antibody, and OIC were also estimated $(\mathrm{r}=0.062, P=0.208 ; \mathrm{r}=-0.028, P$ $=0.355 ;$ and $\mathrm{r}=0.073, P=0.167$, respectively). $\mathrm{A}$ similar result was also found for fat yield in milk, where correlations with cellular, antibody, and OIC were estimated $(\mathrm{r}=0.021, P=0.391 ; \mathrm{r}=0.087, P=0.093$; and $\mathrm{r}=0.038, P=0.307$, respectively).

\section{Additional Health and Other Issues}

Across the 2 herds, the incidence of dystocia (defined as difficulty in calving leading to intervention by the farm management or veterinarian) was 9.0 (95\% CI $=6.4$ to 13) cases per 100 calvings. The incidence of dystocia in herds 1 and 2 was 11 (95\% CI $=6.8$ to 17$)$ and $8.0(95 \% \mathrm{CI}=4.6$ to 12$)$ cases per 100 calvings, respectively. The incidences of retained fetal membranes, defined as lack of expulsion of the placenta by $48 \mathrm{~h}$ pos calving, and metritis, defined as infection of the uterus manifest as the presence of an unclear vaginal discharge up to an including $60 \mathrm{~d}$ postcalving, were 6.0 (95\% CI 
Table 1. Serum cortisol concentrations in animals ranked as above average, average, and below average for antibody, cellular, and overall immune competence $(\mathrm{OIC})^{1}$

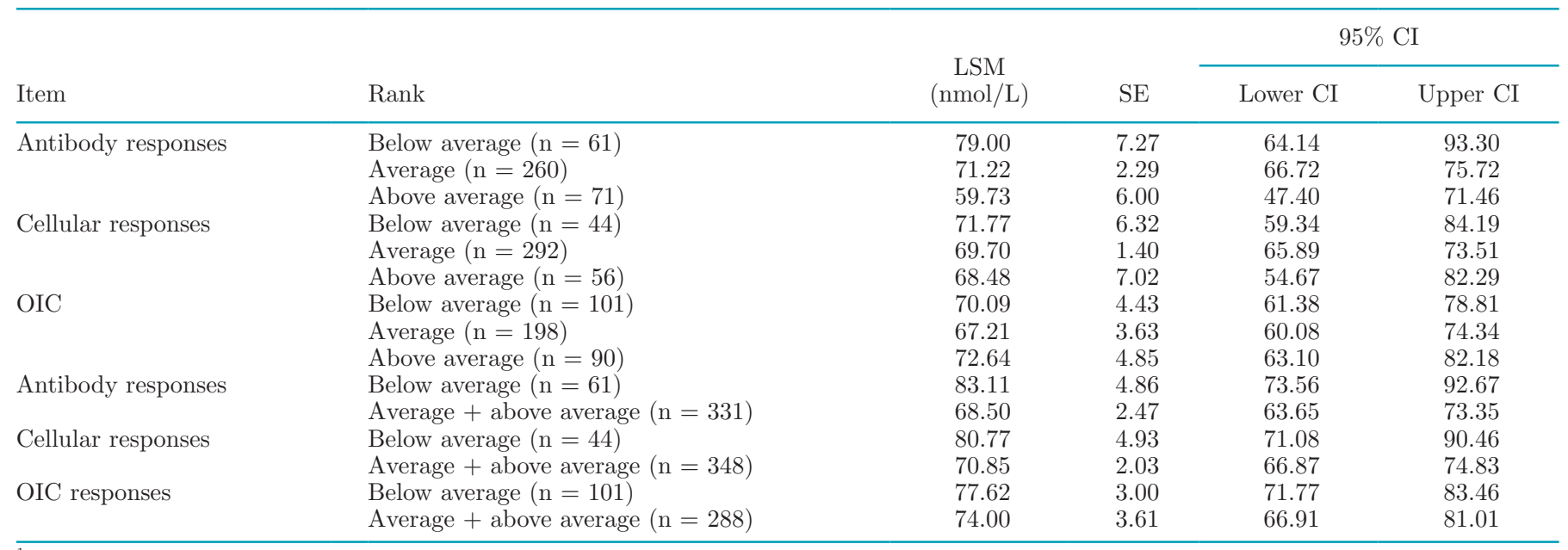

${ }^{1}$ Data represent LSM (and 95\% CI) of serum cortisol concentrations measured following exposure to handling stress on 2 separate occasions. For statistical analysis the fixed effects of farm were fitted to statistical models as a single factor (herd 1, herd 2).

$=3.0$ to 11$)$ and and $7(95 \% \mathrm{CI}=3.5$ to 12$)$ cases per 100 cows, respectively, for herd 1 . In herd 2 , the incidence of retained fetal membranes and metritis were not consistently recorded. Lameness was only observed in 3 heifers in one herd.

\section{DISCUSSION}

The objectives of our study were to assess the antibody and cellular immune responses of dairy yearling heifers aged 12 to 15 mo that were reared under a pasture-based production system and to determine associations between immune competence and stress responsiveness, internal parasite burden, milk production, SCC, milk protein, and milk fat yield. Heifers identified as below average for both their ability to mount antibody and cellular immune responses had higher cortisol concentrations following mustering and handling when compared with their counterparts. Therefore, findings of our study suggest that ability to mount antibody responses was (favorably) correlated with ability to cope with management-induced stress; however, the relationship was not strong $(\mathrm{r}=-0.220$, $P<0.01)$. This association can be considered favorable, as enhanced immune competence was correlated with improved ability to cope with stress (lower cortisol concentrations following handling). Antibody immune responses were also favorably correlated with internal parasite burden as assessed by WEC. No significant differences were observed between immune competence phenotype groupings for cellular, antibody, and OIC immune responses and milk yield, SCC, and fat and protein content. Phenotypic correlations between immune competence traits and milk production traits were generally weak and nonsignificant, with the exception of cellular responses and milk yield, which was favorable and approached significance.

A negative correlation between antibody responses and cortisol response to handling was observed, supporting the hypothesis that increased stress responsiveness is associated with reduced immune competence. Hormones secreted in response to stress include norepinephrine, epinephrine, and glucocorticoids, which can suppress immune function (Eskandari and Sternberg,

Table 2. Serum cortisol concentrations in combined animal immune response phenotypes for antibody, cellular, and overall immune competence $(\mathrm{OIC})^{1}$

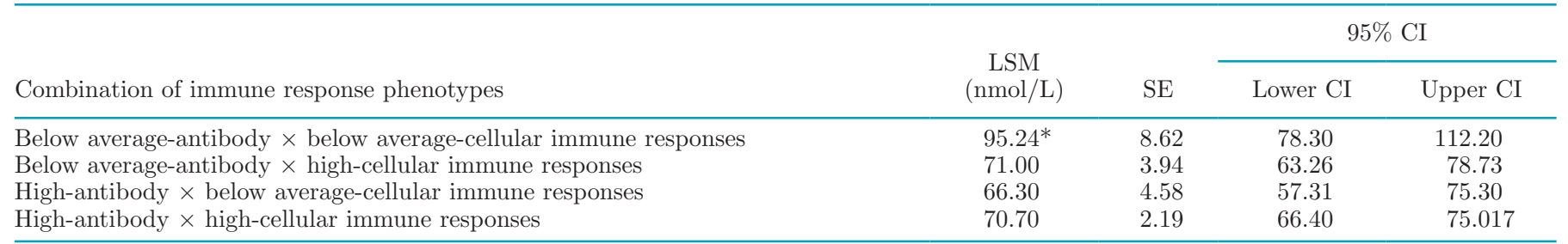

${ }^{1}$ Data represent LSM $(95 \%$ CI $)$ of serum cortisol levels generated using linear mixed models by fitting interactions for the different immune response groups. For statistical analysis the fixed effects of farm were fitted to statistical models as a single factor (herd 1, herd 2).

*Demonstrating significantly higher levels of plasma cortisol concentration $(\mathrm{nmol} / \mathrm{L})$ as compared with the other groups $(P=0.006)$. 


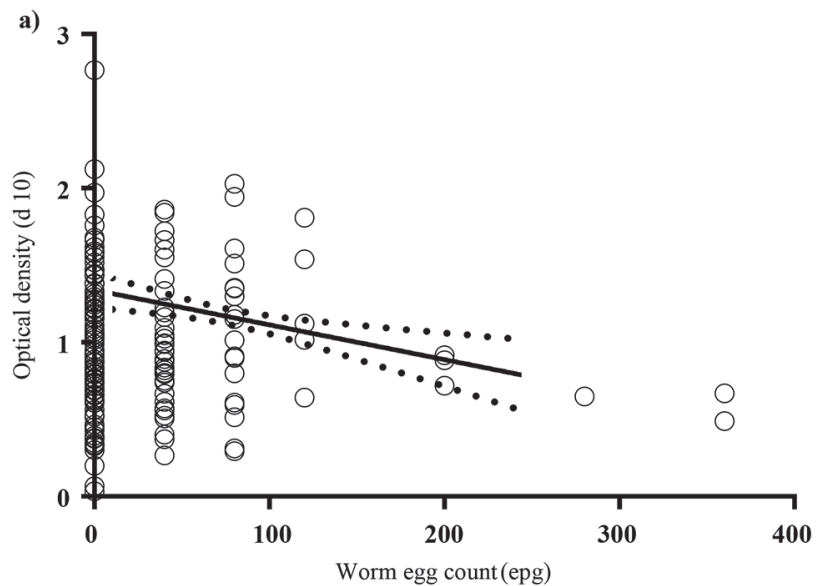

b)
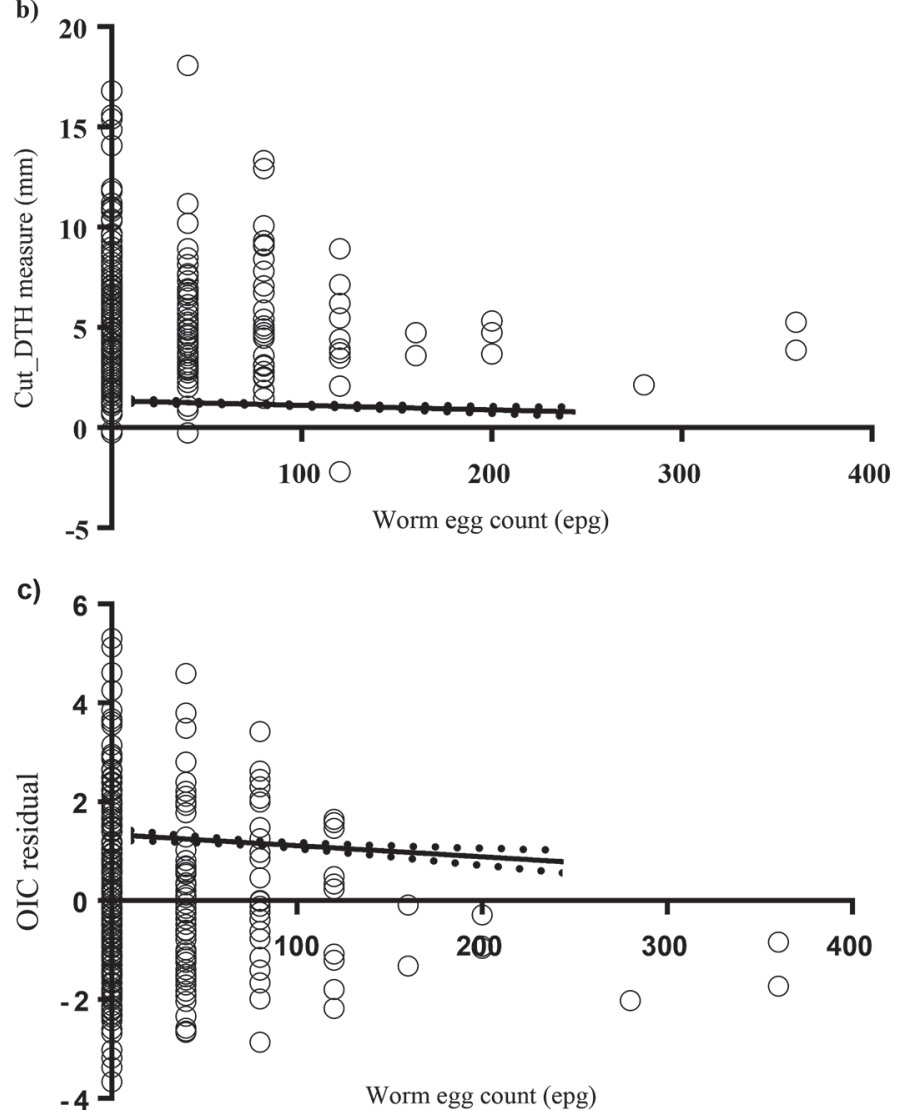

Figure 2. Raw data analysis using GraphPad Prism version 7.00 for Windows, GraphPad Software, La Jolla, CA. (a) Correlation between antibody responses (Ab; d 10) as assessed by measuring production of antitetanus toxoid $\mathrm{IgG}_{1}$ serum antibody in response to vaccination presented as optical density (y-axis) and worm egg counts presented as eggs per gram (epg) of feces (x-axis). (b) Correlation of cellular immunity assessed by measuring the magnitude of skin reactions to vaccine components (in mm; y-axis) and worm epg (x-axis). DTH = delayed-type hypersensitivity. (c) Correlation between overall immune competence (OIC) assessed as combination of antibody and cellular immune response residual values (y-axis) and worm egg counts presented as epg of feces (x-axis). A total of $(72 \%, 281 / 393)$ animals had no presence of worm egg counts. Data present untransformed values. For statistical analysis of correlations between traits, the fixed effects of herd fitted to statistical models as a single factor with 2 levels (herd 1, herd 2). Dotted line represents 95\% CI.
2002; Diez-Fraile et al., 2003). Cortisol is the dominant glucocorticoid in cattle and is produced during stress responses via the hypothalamus-pituitary-adrenal axis (Venkataseshu and Estergreen, 1970). Reduced stress responsiveness is a desirable trait in production systems due to the favorable correlations between ability to cope with management-induced stresses and other desirable production traits, such as growth rate, feed conversion efficiency, and social dominance and behavior (Luiting et al., 1994; Hessing et al., 1995; Knott et al., 2008). Immune competence and stress responsiveness are linked via immunological, physiological, and behavioral mechanisms (Hessing et al., 1994; Knott et al., 2008). The findings of our study also revealed that animals with both below average cellular and antibody immune responses had significantly higher serum cortisol concentrations compared with their average and above-average immune competence counterparts. Links between immune competence, behavioral coping styles, and stress responsiveness have been reported previously in livestock (Colditz and Hine, 2016). Allocation of resources toward biological processes such as coping mechanisms versus production is highly relevant to this area of research and has been reviewed elsewhere (Colditz, 2002). In our study, stress responses to mustering, yarding, and handling were used as a measure of management-induced stress responsiveness (Alam and Dobson, 1986; Mitchell et al., 1988). Cortisol responses on $\mathrm{d} 10($ mean $=76.37 \pm 1.87 \mathrm{nmol} / \mathrm{L})$ and $8($ mean $=63.66 \pm 1.75 \mathrm{nmol} / \mathrm{L})$ were higher than commonly observed basal cortisol concentrations in cattle of approximately $17 \mathrm{nmol} / \mathrm{L}$ (Kaneko et al., 2008), suggesting that mustering and handling of heifers in the current study induced a stress response.

Gastrointestinal nematode infections in young cattle can adversely affect performance, both in terms of growth and reproductive capacity (Charlier et al., 2009). Naïve young stock are usually exposed to gastrointestinal nematodes when they graze on contaminated pastures. Increasing issues associated with anthelmintic resistance has led to renewed interest in alternative nematode control strategies, such as vaccination, use of refugia, and breeding for improved disease resistance. In the current study, a significant but weak negative (favorable) correlation was observed between antibody immune response and WEC. In contrast, correlations between cellular immune responses and WEC and OIC and WEC were nonsignificant. Associations between overall immune competence and internal parasite burden in pasture-based dairy systems have not been reported previously. Internal parasite burden was assessed in our study to improve our understanding of how selection for immune competence may influence resistance to internal parasites. The practice of anthelmintic use in 
heifers and yearlings was a common practice, but this was not the case for adult milking cows. However, it is important to note that cellular and antibody immune responses work together to protect the host against a wide range of pathogens, and therefore selection based on overall immune competence in conjunction with selection to resistance to specific disease of economic importance is expected to provide a more stable and robust approach to improving animal health. Breeding for resistance to a specific disease, predominantly controlled by antibody-mediated immune responses, can lead to susceptibility to diseases predominantly controlled by cell-mediated immune responses and vice versa.

The findings of our study revealed no differences in the milk linear SCS between above-average, average, and below-average immune competence animals when ranked on cellular, antibody, or OIC. A limitation for interpretation of SCC data collected as part of the current study is that heifers observed with mastitis were immediately culled and SCC and production data from these heifers were lost. Of the cases that were followed to the end of the study period (heifers not culled), the average LS across each time period studied were generally below the low positive linear score threshold of $3(100,000$ cells $/ \mathrm{mL})$ used in industry. Our results showed no significant difference between the odds of being culled between immune response groups for antibody, cellular, or OIC. Previous studies have investigated udder health in adult Holstein-Friesians and Norwegian Red $\times$ Holstein-Friesian heifers tested for overall immune responsiveness in housed intensive production systems in North America. (Begley et al., 2009b). In their study, it was observed that superior immune responders recorded a lower incidence of clinical mastitis compared with the low immune responders, in contrast to the findings of our study. The low overall incidence risk of mastitis observed in all heifers during our study (8.1\%) and the loss of SCC data from heifers culled due to contacting mastitis may have contributed to the differences in the findings of each study. The low prevalence of LS obtained in first-lactation heifers has also been observed elsewhere (Nickerson et al., 2008). Somatic cell counts are important parameters in the monitoring of udder health in dairy farms, as indicators of both resistance and susceptibility to mastitis (Sharma et al., 2011). However, a knowledge gap exists on the acceptable minimum threshold for SCC in cows to be defined as physiologically fit while still being able to mount a timely and effective localized immune response when exposed to mastitis-causing pathogens. Due to the limitations associated with the SCC data collected as part of the current study, further case studies will be required to confirm associations between immune competence phenotype groups and milk SCC during first lactation.

No significant differences in milk volume, milk protein, or milk fat yield were observed between animals ranked as above average, average, and below average for cellular, antibody, or OIC in the current study. In contrast, a significant association between cutaneous DTH EBV and milk yield have been reported previously (Thompson-Crispi et al., 2012b). However, the age of animals enrolled in each study differed along with production system type, which may have contributed to the contrasting results. The statistical tendency of $(P=0.061)$ toward significance between higher milk yield and superior immune responders could be viewed as of biological importance, as observed in other studies under the Canadian Mastitis Research Network (Thompson-Crispi et al., 2012b). Associations between immune competence, milk volume, and milk protein and fat yield have not been reported previously in a pasture-based production system. Further studies in multiparous cows reared in grazing systems will provide more insights into these effects.

The concept of breeding animals based on their ability to mount an effective immune response has potential health and welfare benefits realized through enhanced general disease resistance (Thompson-Crispi et al., 2012b; Hine et al., 2014; Mallard et al., 2015). Knowledge of an animal's immune competence can be used to not only inform selection decisions, but also as a management tool to improve on-farm health management practices. For instance, animals identified as low immune responders could be closely monitored, especially at high disease risk periods such as during the periparturient period. The current study forms part of a series of studies conducted in the Australian pasture-based dairy production system to evaluate the potential to select animals with an improved ability to mount immune responses that are expected to exhibit improved general disease resistance (Aleri, 2016). The repeatability of our developed methodology is reported elsewhere (Aleri et al., 2015; Aleri, 2016). In the current study, despite intensive follow-up discussions with herd owners and assessment of on-farm herd health records, losses of animals from the study due to culling and inconsistent recording of periparturient health issues are acknowledged as limitations to the study, which may have potentially biased herd test results and periparturient disease reporting. These limitations were beyond the control of the study investigators and were uncommon practices within the typical Australian pasture-based dairy production system. It is noteworthy, however, that as part of the study design both observers (both herd owners and investigators) were blinded to the immune competence phenotype of animals, as 
this was not determined until the end of the study. Therefore, limitations of the study are not expected to have biased immune competence groupings differentially. The culling of animals during the follow-up period reduced the power of the data generated from the herd test results by $14 \%(80-69 \%)$.

Results of the current study showed no significant differences between immune response groups on the odds of being culled. Furthermore, the low incidence of periparturient diseases recorded on-farm made the assessment of the relationship between immune competence and disease incidence inconclusive in the current study. The culling of mastitic heifers was atypical practice in the Australian pasture-based production system but a common trend in larger farms. Therefore, further studies will be required to investigate associations between immune competence phenotype and disease incidence.

In summary, results from the current study revealed favorable associations exist between immune responsiveness traits and ability to cope management induced stress and internal parasite burden. However, as associations were weak, further studies will be required to validate these findings.

\section{ACKNOWLEDGMENTS}

This study was mainly funded by a grant from the Victorian Department of Economic Development, Jobs, Transport and Resources (Melbourne, Victoria, Australia). We acknowledge the support and funds from the Gustav Rosenberger Memorial Fund (https:// gustavrosenberger.com/) to the recipient (Josh Aleri), which partly supported this study and facilitated intensive training in advanced fields of immunology with Brad Hine (CSIRO laboratory, Armidale, New South Wales, Australia), advanced veterinary epidemiology with Mark Stevenson (University of Melbourne, Werribee, Victoria, Australia), examination with the Australian and New Zealand College of Veterinary Sciences (ANZCVS, https://www.anzcvs.org.au/), and advanced clinical training in dairy medicine with Michael Pyman (University of Melboune and Dairy Australia, Southbank, Victoria, Australia). Special thanks to Theo Lam (Utrecht University, Utrecht, the Netherlands, and GD Animal Health, Deventer, the Netherlands) for his mentorship from a far and for his words of encourage. The authors acknowledge Garry Anderson from University of Melbourne for statistical advice and the owners of the participating farms. We thank the following persons: Bronwyn Stevens, Frances Fitzpatrick and Melanie Conley, Christine Anderson (University of Melbourne), and Dominic Niemeyer (CSIRO) for their valuable technical support.

\section{REFERENCES}

Alam, M. G., and H. Dobson. 1986. Effect of various veterinary procedures on plasma concentrations of cortisol, luteinising hormone and prostaglandin F2 alpha metabolite in the cow. Vet. Rec. 118:7-10. https://doi.org/10.1136/vr.118.1.7.

Aleri, J. 2016. Immune responsiveness as a predictor of health and welfare of dairy cattle in the Australian pasture-based production system. PhD Thesis. Veterinary Science, University of Melbourne, Australia. https://minerva-access.unimelb.edu.au/handle/11343/ 112518.

Aleri, J. W., B. C. Hine, M. F. Pyman, P. D. Mansell, W. J. Wales, B. Mallard, and A. D. Fisher. 2015. Assessing adaptive immune response phenotypes in Australian Holstein-Friesian heifers in a pasture-based production system. J. Anim. Sci. 93:3713-3721. https://doi.org/10.2527/jas.2015-9078.

Aleri, J. W., B. C. Hine, M. F. Pyman, P. D. Mansell, W. J. Wales, B. Mallard, and A. D. Fisher. 2016. Periparturient immunosuppression and strategies to improve dairy cow health during the periparturient period. Res. Vet. Sci. 108:8-17. https://doi.org/10 $.1016 /$ j.rvsc.2016.07.007.

Aleri, J. W., B. C. Hine, M. F. Pyman, P. D. Mansell, W. J. Wales, B. Mallard, and A. D. Fisher. 2017. An assessment of immune and stress responsiveness in Holstein-Friesian cows selected for high and low feed conversion efficiency. Anim. Prod. Sci. 57:244-251. https://doi.org/10.1071/AN15406.

Beausoleil, N. J., D. Blache, K. J. Stafford, D. J. Mellor, and A. D. Noble. 2008. Exploring the basis of divergent selection for 'temperament' in domestic sheep. Appl. Anim. Behav. Sci. 109:261-274. https://doi.org/10.1016/j.applanim.2007.03.013.

Begley, N., F. Buckley, E. B. Burnside, L. Schaeffer, K. Pierce, and B. A. Mallard. 2009a. Immune responses of Holstein and Norwegian Red x Holstein calves on Canadian dairy farms. J. Dairy Sci. 92:518-525. https://doi.org/10.3168/jds.2008-1300.

Begley, N., F. Buckley, K. M. Pierce, A. G. Fahey, and B. A. Mallard. 2009b. Differences in udder health and immune response traits of Holstein-Friesians, Norwegian Reds, and their crosses in second lactation. J. Dairy Sci. 92:749-757. https://doi.org/10.3168/jds .2008-1356.

Berry, D. P., F. Buckley, P. Dillon, R. Evans, M. Rath, and R. Veerkamp. 2003. Genetic parameters for body condition score, body weight, milk yield, and fertility estimated using random regression models. J. Dairy Sci. 86:3704-3717. https://doi.org/10 .3168/jds.S0022-0302(03)73976-9.

Brightling, P., R. Dyson, A. Hope, and J. Penry. 2009. A national programme for mastitis control in Australia: Countdown downunder. Ir. Vet. J. 62(Suppl. 4):S52-S58.

Burton, J. L., E. B. Burnside, B. W. Kennedy, B. N. Wilkie, and J. H. Burton. 1989. Antibody responses to human erythrocytes and ovalbumin as marker traits of disease resistance in dairy calves. J. Dairy Sci. 72:1252-1265. https://doi.org/10.3168/jds.S0022 -0302(89)79230-4.

Charlier, J., J. Höglund, G. von Samson-Himmelstjerna, P. Dorny, and J. Vercruysse. 2009. Gastrointestinal nematode infections in adult dairy cattle: Impact on production, diagnosis and control. Vet. Parasitol. 164:70-79. https://doi.org/10.1016/j.vetpar.2009 .04 .012 .

Colditz, I. G. 2002. Effects of the immune system on metabolism: implications for production and disease resistance in livestock. Livest. Prod. Sci. 75:257-268. https://doi.org/10.1016/S0301 $-6226(01) 00320-7$.

Colditz, I. G., and B. C. Hine. 2016. Resilience in farm animals: Biology, management, breeding and implications for animal welfare. Anim. Prod. Sci. 56:1961-1983. https://doi.org/10.1071/AN15297.

Cummins, S. B., P. Lonergan, A. Evans, D. P. Berry, R. D. Evans, and S. T. Butler. 2012. Genetic merit for fertility traits in Holstein cows: I. Production characteristics and reproductive efficiency in a pasture-based system. J. Dairy Sci. 95:1310-1322. https://doi.org/ $10.3168 / \mathrm{jds} .2011-4742$

Diez-Fraile, A., E. Meyer, C. Burvenich, and C. Burvenich. 2003. Sympathoadrenal and immune system activation during the peripartu- 
rient period and their association with bovine coliform mastitis. A review. Vet. Q. 25:31-44. https://doi.org/10.1080/01652176.2003 .9695142

Dohoo, I. R., W. Martin, and H. Stryhn. 2012. Methods in Epidemiologic Research. VER Inc., Charlottetown, Prince Edward Island, Canada.

Dupont, W. D., and W. D. Plummer. 1990. Power and sample size calculations: A review and computer program. Control. Clin. Trials 11:116-128. https://doi.org/10.1016/0197-2456(90)90005-M.

Edwards, E. 2014 Preliminary investigation into mastitis rates as a predictor for bovine tuberculosis susceptibility and the possibility of implementation of High Immune Response dairy cows. BSc Thesis, Department of Agriculture, Royal Agricultural University, Cirencester, United Kingdom.

Eskandari, F., and E. M. Sternberg. 2002. Neural-immune interactions in health and disease. Ann. N. Y. Acad. Sci. 966:20-27.

Heriazon, A., J. Yager, W. Sears, and B. Mallard. 2009. Induction of delayed-type hypersensitivity and interferon-gamma to Candida albicans and anti-hen-egg white lysozyme antibody as phenotypic markers of enhanced bovine immune response. Vet. Immunol. Immunopathol. 129:93-100. https://doi.org/10.1016/j.vetimm.2008 .12 .019 .

Hessing, M. J. C., G. J. Coenen, M. Vaiman, and C. Renard. 1995. Individual differences in cell-mediated and humoral immunity in pigs. Vet. Immunol. Immunopathol. 45:97-113. https://doi.org/10 .1016/0165-2427(94)05338-S.

Hessing, M. J. C., C. J. M. Scheepens, W. G. P. Schouten, M. J. M. Tielen, and P. R. Wiepkema. 1994. Social rank and disease susceptibility in pigs. Vet. Immunol. Immunopathol. 43:373-387. https:/ /doi.org/10.1016/0165-2427(94)90158-9.

Hine, B. C., S. L. Cartwright, and B. A. Mallard. 2011. Effect of age and pregnancy status on adaptive immune responses of Canadian Holstein replacement heifers. J. Dairy Sci. 94:981-991. https://doi .org/10.3168/jds.2010-3329.

Hine, B. C., B. A. Mallard, A. B. Ingham, and I. G. Colditz. 2014. Immune competence in livestock. Pages 49-64 in Breeding Focus 2014 Improving Resilience. S. Hermesch, and S. Dominik, ed. Animal Genetics and Breeding Unit, University of New England, Armidale, Australia.

Kaneko, J. J., J. W. Harvey, and M. L. Bruss. 2008. Clinical Biochemistry of Domestic Animals. Academic Press, London, United Kingdom.

Kassai, T. 2002. Veterinary Helminthology. Acribia SA, Zaragoza, Spain.

Kirkpatrick, M., D. Lofsvold, and M. Bulmer. 1990. Analysis of the inheritance, selection and evolution of growth trajectories. Genetics 124:979-993.

Knott, S. A., L. J. Cummins, F. R. Dunshea, and B. J. Leury. 2008. Rams with poor feed efficiency are highly responsive to an exogenous adrenocorticotropin hormone (ACTH) challenge. Domest. Anim. Endocrinol. 34:261-268. https://doi.org/10.1016/j .domaniend.2007.07.002.

Kossaibati, M. A., and R. J. Esslemont. 1997. The costs of production diseases in dairy herds in England. Vet. J. 154:41-51. https://doi .org/10.1016/S1090-0233(05)80007-3.

Luiting, P., E. M. Urff, and M. W. A. Verstegen. 1994. Betweenanimal variation in biological efficiency as related to residual feed consumption. Neth. J. Agric. Sci. 42:59-67.

Mallard, B. A., M. Emam, M. Paibomesai, K. Thompson-Crispi, and L. Wagter-Lesperance. 2015. Genetic selection of cattle for improved immunity and health. Jpn. J. Vet. Res. 63:S37-S44. https: //doi.org/10.14943/jjvr.63.suppl.s37.

Miglior, F., B. L. Muir, and B. J. Van Doormaal. 2005. Selection indices in Holstein cattle of various countries. J. Dairy Sci. 88:12551263. https://doi.org/10.3168/jds.S0022-0302(05)72792-2.

Mitchell, G., J. Hattingh, and M. Ganhao. 1988. Stress in cattle assessed after handling, after transport and after slaughter. Vet. Rec. 123:201-205.

Moore, S. G., S. Scully, J. A. Browne, T. Fair, and S. T. Butler. 2014. Genetic merit for fertility traits in Holstein cows: V. Fac- tors affecting circulating progesterone concentrations. J. Dairy Sci. 97:5543-5557. https://doi.org/10.3168/jds.2014-8133.

National Health and Medical Research Council. 1990. Australian code of practice for the care and use of animals for scientific purposes. National Health and Medical Research Council, Commonwealth Scientific and Industrial Research Organization, Australian Agricultural Council. Australian Government Publishing Service, Canberra.

Nickerson, S., E. Hovingh, P. Widel, and T. Lam. 2008. Immunisation of dairy heifers with a Staphylococcus aureus bacterin reduces infection level and somatic cell counts at time of calving. Page 119 in Proc. Mastitis Control: From Science to Practice: Proceedings of International Conference 30 September-2 October 2008, The Hague, the Netherlands. Wageningen Academic Publishers, Wageningen, the Netherlands.

Oltenacu, P. A., and D. M. Broom. 2010. The impact of genetic selection for increased milk yield on the welfare of dairy cows. Anim. Welf. 19(Suppl.):39-49.

Pighetti, G. M., and L. Sordillo. 1996. Specific immune responses of dairy cattle after primary inoculation with recombinant bovine interferon-gamma as an adjuvant when vaccinating against mastitis. Am. J. Vet. Res. 57:819-824.

Price, R. E., J. W. Templeton, R. Smith, and L. G. Adams. 1990. Ability of mononuclear phagocytes from cattle naturally resistant or susceptible to brucellosis to control in vitro intracellular survival of Brucella abortus. Infect. Immun. 58:879-886.

Schukken, Y. H., D. J. Wilson, F. Welcome, L. Garrison-Tikofsky, and R. N. Gonzalez. 2003. Monitoring udder health and milk quality using somatic cell counts. Vet. Res. 34:579-596. https://doi.org/10 .1051 /vetres:2003028.

Sharma, N., N. Singh, and M. Bhadwal. 2011. Relationship of somatic cell count and mastitis: An overview. Asian-Australas. J. Anim. Sci. 24:429-438. https://doi.org/10.5713/ajas.2011.10233.

Stevenson, M., T. Nunes, C. Heuer, J. Marshall, J. Sanchez, R. Thornton, J. Reiczigel, J. Robinson-Cox, P. Sebastiani, P. Solymos, K. Yoshida, G. Jones, S. Pirikahu, S. Firestone, R. Kyle, J. Popp, and M. Jay. 2015. Tools for the Analysis of Epidemiological Data. Version 0.9-99. Accessed Jan. 25, 2019. https://cran.r-project.org/ web/packages/epiR/epiR.pdf

Stoop, C. L., K. A. Thompson-Crispi, S. L. Cartwright, and B. A. Mallard. 2016. Short communication: Variation in production parameters among Canadian Holstein cows classified as high, average, and low immune responders. J. Dairy Sci. 99:4870-4874. https:// doi.org/10.3168/jds.2015-10145.

Thompson-Crispi, K. A., B. Hine, M. Quinton, F. Miglior, and B. A. Mallard. 2012a. Association of disease incidence and adaptive immune response in Holstein dairy cows. J. Dairy Sci. 95:3888-3893. https://doi.org/10.3168/jds.2011-5201.

Thompson-Crispi, K. A., A. Sewalem, F. Miglior, and B. A. Mallard. 2012b. Genetic parameters of adaptive immune response traits in Canadian Holsteins. J. Dairy Sci. 95:401-409. https://doi.org/10 .3168/jds.2011-4452.

Uribe, H. A., B. W. Kennedy, S. W. Martin, and D. F. Kelton. 1995. Genetic parameters for common health disorders of Holstein cows. J. Dairy Sci. 78:421-430. https://doi.org/10.3168/jds.S0022 -0302(95)76651-6.

Venkataseshu, G. K., and V. L. Estergreen Jr. 1970. Cortisol and corticosterone in bovine plasma and the effect of adrenocorticotropin. J. Dairy Sci. 53:480-483. https://doi.org/10.3168/jds.S0022 -0302(70)86234-8.

Wagter, L. C., B. A. Mallard, B. N. Wilkie, K. E. Leslie, P. J. Boettcher, and J. C. M. Dekkers. 2003. The relationship between milk production and antibody response to ovalbumin during the peripartum period. J. Dairy Sci. 86:169-173. https://doi.org/10.3168/ jds.S0022-0302(03)73597-8.

Wales, W. J., and E. S. Kolver. 2017. Challenges of feeding dairy cows in Australia and New Zealand. Anim. Prod. Sci. 57:1366-1383. https://doi.org/10.1071/AN16828. 